\title{
Macrokinetic Analysis of Refractory Compound Synthesis Using the Electro-Thermal Explosion Method
}

\author{
A.P. Aldushin \\ A.G. Merzhanov Institute of Structural Macrokinetics and Materials Science Problems of the Russian Academy of Sciences (ISMAN), \\ ul. Academician Osipyan, 8, Chernogolovka, Moscow Region, 142432, Russia
}

Corresponding author. Tel.: +791653434 76.E-mail: analdushin@mail.ru

\begin{abstract}
From the standpoint of the classical theory of combustion, the analysis of the electro-thermal explosion (ETE) of heterogeneous condensed systems has been carried out. The ETE is one of the variants of a dynamic thermal explosion in which an exothermic reaction proceeds under conditions of heating a substance by passing an electric current. The rate of solid-phase interaction of reagents in condensed mixtures is very low due to low values of diffusion coefficients and undeveloped contact areas of solid particles. A sharp acceleration of the reaction occurs when one of the reactants melts and spreads in the pore space. In the approximation of a negligibly small rate of interaction of solid-phase reagents, estimates of the main characteristics of an electro-thermal explosion were obtained. The critical power of the current separating the steady state and the explosive mode of the process has been determined; the explosion induction period has been calculated; the maximum temperature of the reaction products has been estimated. It is shown that the ETE in mixtures of refractory reagents can lead to extremely high temperatures of the reaction medium.
\end{abstract}

\section{Keywords}

Combstion macrokinetics; thermal explosion; reactions in powder mixtures; synthesis of refractory compounds.

(C) A.P. Aldushin, 2019

\section{Introduction}

The electro-thermal explosion (ETE) is one of the options for the implementation of the synthesis of refractory compounds. Unlike layer-by-layer combustion of a substance in the process of selfpropagating high-temperature synthesis (SHS), with the ETE, the reaction proceeds simultaneously throughout the entire volume of the reaction mass as a result of direct transmission of electric current through the sample. The principal possibility of the synthesis of compounds by the ETE method was demonstrated both on binary [1,2] and composite [3] systems. In addition to technological interest in the original direction of the synthesis of compounds, the ETE process attracts attention in terms of an effective method for studying the macrokinetics of high-temperature exothermic transformations in the SHS. In ideological terms, the methods of studying the macrokinetics of reactions in the ETE processes use the same scheme as in the classical thermal explosion (TE) with surface heating of the reacting volume. In the latter case, the information obtained on the kinetic characteristics of the process refers to the low-temperature interval in the vicinity of the ambient temperature. The ETE method, which uses the rapid volume heating of the medium, is aimed at studying the macrokinetics reaction in a wide temperature range, including the high-temperature stages of the process. The experimental studies of the ETE in SHS systems have been performed in many papers, see, for example $[4,5]$. Mathematical modeling of the process was carried out in [6] under the assumption of the Arrhenius dependence of the reaction rate constant on temperature without taking into account possible phase transformations of the components of the mixture.

The features of the interaction macrokinetics in SHS systems are associated with the heterogeneity of the medium and the need for strong heating for the reaction to proceed at a significant rate. Among researchers of the SHS process, it is widely believed that the intense exothermic interaction in condensed 
mixtures begins only after one of the reagents melts. Direct experimental confirmation of this thesis can be found in [7] on the ignition of titanium filaments coated with a layer of soot. The results of the study of the ETE in the Ti-C system [4] lead to a similar conclusion. The authors of [4] recorded the absence of noticeable reaction heat generation at temperatures below the melting point of titanium $T_{\mathrm{m}}$ and a sharp jump in the reaction rate at $T>T_{\mathrm{m}}$. The influence of the phase transition on the rate of heat generation is associated with an increase in the surface of heterogeneous interaction as a result of the spreading of the molten reactant through solid particles and the transition from a solid-phase reaction to a solid-melt interaction. In the present study, the analysis of the ETE is carried out, taking into account the specificity of the kinetics of heat release in the systems with a meltable reactant mixture.

\section{Statement of the problem}

A cylindrical sample with a radius $R$ and length $l$ of the reaction condensed mixture is clamped between the electrodes to which a constant voltage $U$ is applied. With a sufficiently large sample length, the end heat loss and temperature heterogeneity along the sample can be ignored. Assuming the high value of the $\mathrm{Bi}$ criterion, due to the high thermal conductivity of the medium, we can neglect the temperature difference between the wall and the center of the sample and consider the problem in the classical setting of N.N. Semenov. The thermal balance of the reaction mixture heated by electric current can be written as

$$
C \frac{d T}{d t}=\Phi-\alpha\left(T-T_{0}\right) ; \quad \Phi=Q W+P .
$$

The heat release rate $\Phi$ at the ETE is determined by the sum of two sources - Joule heating and chemical energy release. Here, $t$ is time, $T, T_{0}$ are current and initial temperatures, $P$ is specific (per unit mass of the sample) current power, $W$ is mass burnout rate, $Q$ is thermal effect of the reaction. Value $\alpha$, characterizing the heat loss from the reacting volume, is determined by the expression $\alpha=\mathrm{Nu} \lambda / R^{2} \rho$, where $\mathrm{Nu}$ is Nusselt number, $\lambda$ is ambient thermal conductivity, pis density, $R$ is sample radius.

The specific thermal capacity $C$ of the mixture, taking into account the phase transition, can be represented as $C=c+L \delta\left(T-T_{\mathrm{m}}\right)$, where $c$ is ambient thermal capacity at $T \neq T_{\mathrm{m}}, L$ is specific heat of fusion, $\delta$ is delta function. Equation (2) is considered together with the kinetic equation (2), which determines the depth of completion of the reaction $\eta$

$$
\begin{gathered}
\frac{d \eta}{d t}=W ; \quad W=K(T) f(\eta) ; \\
K\left(T<T_{\mathrm{m}}\right)=0 ; \quad K\left(T>T_{\mathrm{m}}\right)=k .
\end{gathered}
$$

Initial conditions for (1), (2):

$$
t=0 ; \quad T=T_{0} ; \eta=0
$$

The approximation of the rate constant by a step function was proposed in [4], based on the experimental data obtained in the study of the ETE in the Ti-C system.

\section{Adiabatic explosion}

With a large Joule heating power $P$, the heat loss can be neglected $(\alpha=0)$ and the temporal characteristics of the adiabatic ETE and the maximum temperature $T_{\max }$ reached at the time of completion of the reaction $(\eta=1)$ can be measured. The development of the ETE process, determined by the solution of the problem (1) - (3) when $P>>\alpha\left(T-T_{0}\right)$, is shown in Fig. 1. The left part of the figure shows the temperature change with time, the right part shows the dependence of the temperature on the reaction depth. The temperature curve $T(t)$ includes three sections inert heating of the mixture by electric current to the melting temperature of the most fusible reagent (1), isothermal melting (2), and heating of the mixture due to chemical and electrical heat sources (3). The period of induction of the explosion $t_{\text {ind }}$ is determined by the moment of completion of melting and the beginning of an intense reaction. Having experimental information about the slopes of straight lines 1 and 2 at a given current power, it is possible to estimate the value of the reaction rate constant:

$$
k=P \frac{\operatorname{tg} \alpha}{\operatorname{tg} \beta-1} .
$$

The right part of Fig. 1 illustrates the ETE process on the phase plane $T-\eta$. In contrast to the classical version of the thermal explosion (dashed line), which implies a final reaction rate at the initial temperature $\mathrm{T}_{0}$; under the ETE, the substance is heated during the induction period (the vertical part of the $T(\eta)$ curve) by the electric current without spending the mixture reagents. 


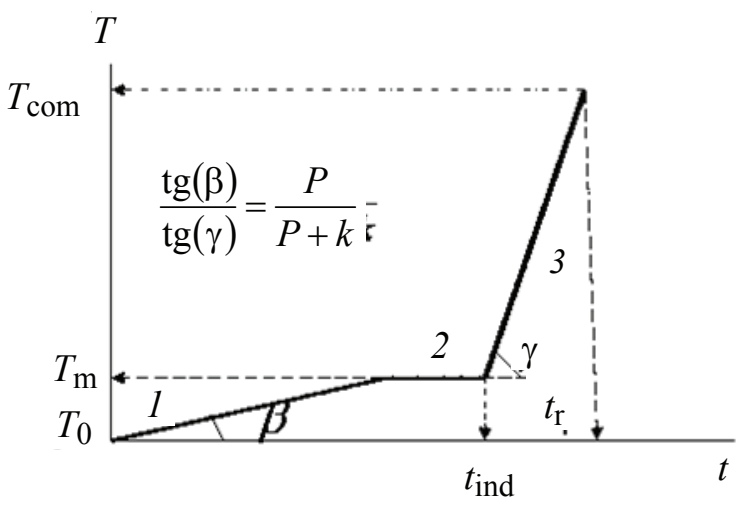

a)

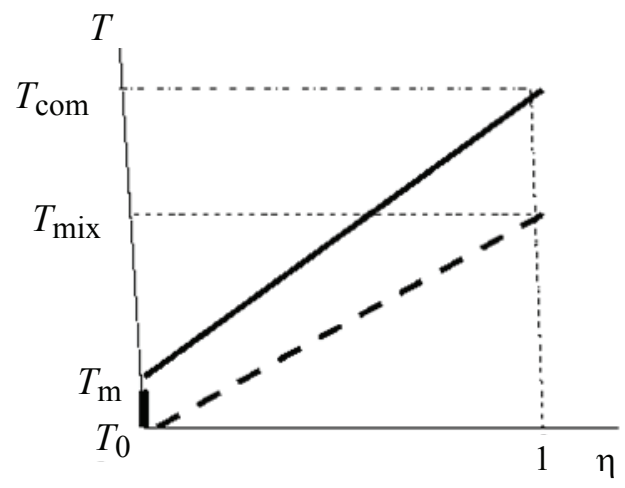

b)

Fig. 1. ETE thermograms:

$a-T_{0}$ is initial temperature, $T_{\mathrm{m}}$ is melting temperature, $T_{\text {com }}$ is combustion temperature;

$b$ - correlations $T(\eta)$ in the case of the classical thermal explosion of homogeneous systems (dotted straight line) and the ETE in heterogeneous condensed mixtures (solid line); $T_{\operatorname{mix}}$ is adiabatic combustion temperature of the mixture

Period of adiabatic induction of an explosion $t_{\text {ind }}$ (melt formation time), reaction time $t_{\mathrm{r}}$, and value $T_{\text {com }}$, found from the solution (1) - (2) are:

$$
\begin{gathered}
t_{\text {ind }}=\frac{c\left(T_{\mathrm{m}}-T_{0}\right)+L}{P} ; \quad t_{\mathrm{r}}=\frac{1}{k} ; \\
T_{\text {com }}=T_{\mathrm{m}}+\frac{Q}{c}+\frac{P \varphi}{k c} ; \quad \varphi=\int_{0}^{1} f^{-1}(\eta) d \eta,
\end{gathered}
$$

respectively.

Coefficient $\varphi$ characterizes the effect of the dependence of the reaction rate on $\eta$. In short-stop reactions with the depth of conversion the value $\varphi>1$.

The above estimate $T_{\text {com }}$ shows that at a high melting point of the reagent in the ETE process, extremely high temperatures can be achieved. Even when the current is turned off after the induction period, the value $T_{\text {com }}$ is

$$
T_{\text {com }}^{0}=T_{\text {mix }}+T_{\mathrm{m}}-T_{0},
$$

where $T_{\text {mix }}$ is the combustion temperature of the mixture at the initial temperature $T_{0}$.

For the $\mathrm{Ti}-\mathrm{C}$ system $\left(T_{\mathrm{m}}=1943 \mathrm{~K}, T_{\text {mix }}=3210 \mathrm{~K}\right.$ [8], $\left.T_{\mathrm{com}}^{0}=4880 \mathrm{~K}\right)$ in the course of ETE, temperatures above the boiling point of titanium carbide $(4573 \mathrm{~K})$ can be reached.

\section{The heat loss effect}

Considering the possibility of achieving extremely high temperatures in the ETE process, it is necessary to evaluate the effect of heat sink into the environment, considering the solution of problem (1) - (3) at the final value of the heat dissipation factor $\alpha$.

To analyze the ETE under conditions of heat exchange with the environment, N.N. Semyonov' diagram, which for the accepted model of interaction of reagents has the form shown in Fig. 2, is proposed.

The horizontal straight lines $1-4$ in Fig. 2 represent the heat release rate at various values of the Joule heating power $P$. Line 1 corresponds to the absence of current $(P=0)$, line $2-4$ corresponds to increasing values of heating power $\left(0<P_{2}<P_{3}<P_{4}\right)$.

The exothermic conversion begins after the melting of one of the reagents at a temperature $T_{\mathrm{m}}$, which corresponds to a jump in the reaction rate $W$, which, assuming a zero order reaction, remains constant at $T>T_{\mathrm{m}}$ and $\eta<1$. The intersection of lines $1-4$ with a direct heat dissipation 5 determines the

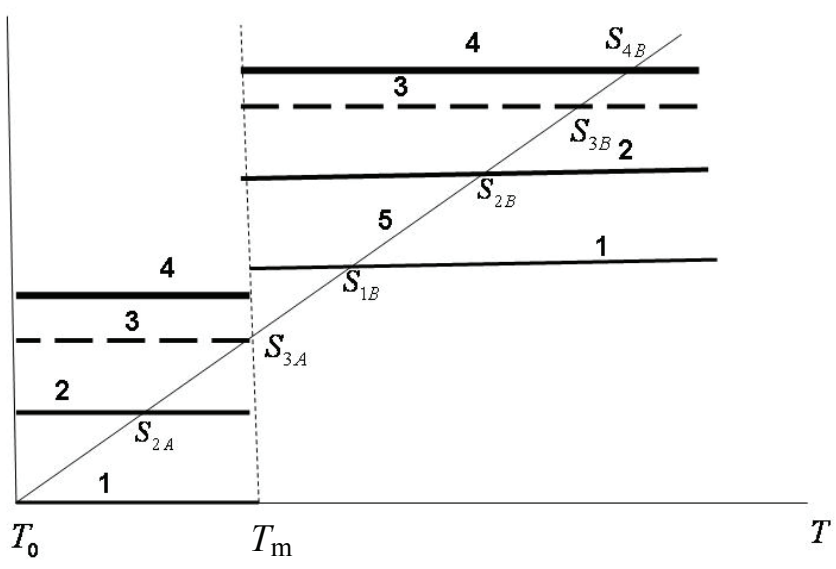

Fig. 2. N.N. Semyonov' diagram for the ETE 
potentially possible points $S$ of the stationary state of the system. At insufficiently high heating rates, thermal equilibrium is reached at a temperature below the melting point (point $S_{2 A}$ ) and the substance burnout does not occur. To start the reaction it is necessary to exceed the critical power $P_{3}$. With supercritical power $\left(P_{4}\right)$, ignition occurs and the transition to a hightemperature burn-out mode. From equation (1) it follows that the critical value of the current power $P_{3}$ separating the inert heating and the combustion mode is

$$
P_{3}=\alpha\left(T_{\mathrm{m}}-T_{0}\right) .
$$

The period of induction of an explosion, defined as the time required to melt the reagent, is equal to

$$
t_{\text {ind }}=\frac{c}{\alpha} \ln \left[\frac{P}{P-\alpha\left(T_{\mathrm{m}}-T_{0}\right)}\right]+\frac{L}{P-\alpha\left(T_{\mathrm{m}}-T_{0}\right)} .
$$

To determine the temperature $T_{\text {com }}$ reached at the end of the reaction, it is necessary to integrate the equation (9) obtained by dividing (1) by (2) in the interval $0<\eta<1\left(T_{\mathrm{m}}<T<T_{\text {com }}\right)$ :

$$
\frac{d T}{d \eta}=\frac{Q W+P-\alpha\left(T-T_{0}\right)}{c W} .
$$

In the approximation of the zero order of the reaction temperature $T_{\text {com }}$ is determined by the expression

$$
\begin{gathered}
T_{\text {com }}=T_{0}+\frac{\left(T_{\text {mix }}-T_{0}\right) k c}{\alpha}\left\{1+\frac{P}{\left(T_{\text {mix }}-T_{0}\right) k c}-\right. \\
\left.-\left[1+\frac{P}{\left(T_{\text {mix }}-T_{0}\right) k c}-\frac{\alpha\left(T_{\mathrm{m}}-T_{0}\right)}{\left(T_{\text {mix }}-T_{0}\right) k c}\right] \exp \left(-\frac{\alpha}{c k}\right)\right\} .
\end{gathered}
$$

When the current is turned off after ignition of the mixture, the temperature at the completion of the reaction reaches

$$
\begin{gathered}
T_{\mathrm{com}}^{0}=T_{0}+\frac{\left(T_{\mathrm{mix}}-T_{0}\right) k c}{\alpha}+ \\
+\left\{1-\left[1-\frac{\alpha\left(T_{\mathrm{m}}-T_{0}\right)}{\left(T_{\mathrm{mix}}-T_{0}\right) k c}\right] \exp \left(-\frac{\alpha}{c k}\right)\right\} .
\end{gathered}
$$

The dimensionless parameter that determines the effect of external heat transfer on the ETE process is the value $A=\alpha / c k$. For small values $A$ the expressions (10), (11) tend to expressions (5) and (6), respectively.

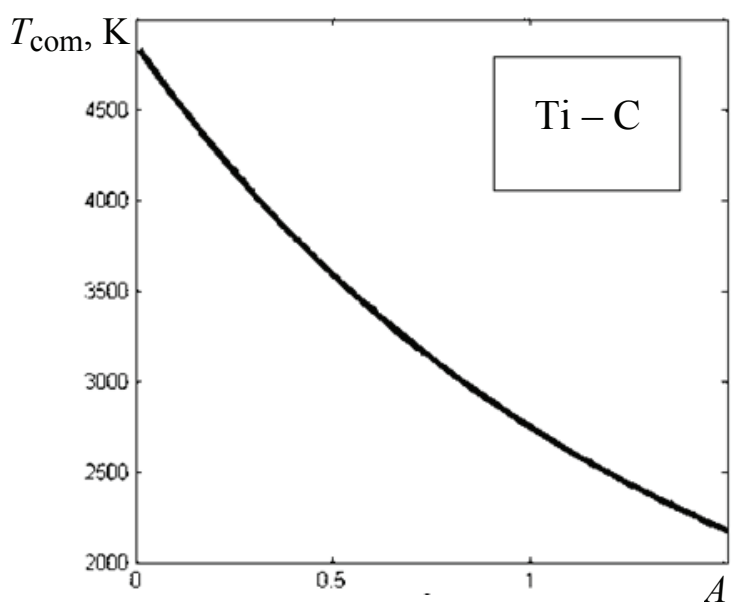

Fig. 3. Correlation of combustion temperature $T_{\text {com }}$ and the heat exchange parameter $A$ when the current is turned off at the time of the start of the reaction

\section{Conclusion}

In contrast to the classical thermal explosion of homogeneous systems, the maximum temperature at ETE of heterogeneous condensed mixtures can significantly exceed the thermodynamic temperature of combustion. An increase in temperature is achieved by heating the mixture with an electric current during the induction period preceding the start of the reaction. In systems with refractory reagents requiring heating to high temperatures to initiate a chemical interaction, the energy contribution of the current to the heating of the system can be very significant and lead to extreme states of matter during an electrothermal explosion.

It should be noted that the effect of high overheating of the environment is a specific feature of the ETE process. Under wave modes of hightemperature synthesis with melting of refractory reagent, this effect does not take place and the temperature of the products does not exceed the thermodynamic value.

\section{References}

1. Knyazik V.A., Merzhanov A.G., Shteinberg A.S. $\mathrm{K}$ voprosu o mekhanizme goreniya sistemy titan uglerod [To the question about the mechanism of combustion of the titanium - carbon system]. Doklady ANCCCP, 1988, vol.301, pp. 899-902 (Rus)

2. Knyasik V.A., Shteinberg A.S. HighTemperature Interaction in the $\mathrm{Ta}-\mathrm{C}$ System under Electrothermal Explosion Conditions. Journal of Materials Synthesis and Processing, 1993 vol. 1, issue 2, pp. 85-92. 
3. Telepa V.T., Shcherbakov V.A., Shcherbakov A.V. TiC-30 wt. \% Fe Composite by PressureAssisted Electrothermal Explosion Letters on Materials. 2016, vol. 6, issue 4, pp. 286.

4. Shcherbakov V.A., Gryadunov A.N., Alymov M.I., Sachkova N.V. Combustion synthesis and consolidation $\mathrm{B} 4 \mathrm{C}-\mathrm{TiB}_{2}$ composites. Letters on Materials. 2016, vol. 6, issue 3, pp. 217.

5. Shcherbakov V.A., Gryadunov A.N., Alymov M.I. Synthesis and Characteristics of the $\mathrm{B}_{4} \mathrm{C}-$ $\mathrm{ZrB}_{2}$ Composites. Letters on Materials. 2017, vol. 7, issue 4, pp. 398-401.

6. Telepa V.T., Alymov M.I., Shcherbakov V.A., Shcherbakov A.V., Vershinnikov V.I. Synthesis of the $\mathrm{WC}-\mathrm{W}_{2} \mathrm{C}$ composite by electro-thermal explosion under pressure. Letters on Materials. 2018, vol. 8, issue 2, pp. 119-122.

7. Knyasik V.A., Merzhanov A.G., Solomonov V.B., Shteinberg A.S. Fizika goreniya $i$ vzryva [Physics of combustion and explosion], 1985, vol. 21, issue 3, pp. 69-73. (Rus)

8. Popov K.V., Knyasik V.A., Shteinberg A.S. Issledovanie vysokotemperaturnogo vzaimodejstviya $\mathrm{Ti}$ s W metodom ehlektroteplovogo vzryva [Study of high-temperature interaction of $\mathrm{Ti}$ with $\mathrm{W}$ by the method of electrothermal explosion]. Fizika goreniya $i$ varyva [Physics of combustion and explosion], 1993, vol. 27, issue 1, pp. 82-87. (Rus)

9. Bostandzhiyan S.A., Gordopolova I.S., Shcherbakov V.A. Modelirovanie ehlektroteplovogo vzryva $\mathrm{v}$ bezgazovyh sistemah, pomeshchennyh $\mathrm{v}$ ehlektroprovodnuyu sredu [Simulation of an electrothermal explosion in gas-free systems placed in an electrically conductive medium]. Fizika goreniya $i$ vzryva [Physics of combustion and explosion], 2013, vol. 49, issue 6, pp. 53-61. (Rus)

10. Vadchenko S.G., Grigoryev Yu.M., Merzhanov A.G. Issledovanie mekhanizma vosplameneniya i goreniya sistem $\mathrm{Ti}+\mathrm{C}, \quad \mathrm{Zr}+\mathrm{C}$ ehlektrotermograficheskim sposobom [Investigation of the mechanism of ignition and combustion of $\mathrm{Ti}+\mathrm{C}, \mathrm{Zr}+\mathrm{C}$ systems by electrothermographic method]. Fizika goreniya $i$ vzryva [Physics of combustion and explosion], 1976, issue 12, pp. 26-31. (Rus)

11. Levashov E.A., Rogachev A.S., Yukhvid V.Yu., Borovinskaya I.P. Fiziko-himicheskie $i$ tekhnologicheskie osnovy samorasprostranyayushchegosya vysokotemperaturnogo sinteza [Physico-chemical and technological bases of self-propagating hightemperature synthesis]. Moscow, Izd-vo Binom, 1999, 175 p. (Rus) 